\title{
Estimating the current and future prevalence of atrial fibrillation in the Australian adult population
}

\section{These data are indicative of a largely under- appreciated \\ AF prevalence in Australia}

Jocasta Ball BBiomedSci(Hons), PhD David R Thompson

Chantal F Sk BA(Hons), PhD

Melinda J Carrington PhD, PostgradDip(Psych)

Tracey Gerber $\mathrm{PhD}^{1,2}$

Simon Stewart $\mathrm{PhD} \mathrm{D}^{1,2}$

1 Mary MacKillop Institute for Health Research, Australian Catholic University, Melbourne, VIC

2 Baker IDI Heart and Diabetes Institute, Melbourne, VIC

Simon.Stewart@ acu.edu.au

doi: 10.5694/mjal4.00238
A trial fibrillation (AF) is the most common sustained cardiac arrhythmia observed in medical practice. It ranges in severity, from isolated and benign episodes of electrical disturbance to a chronic cardiac condition that results in cardiac remodelling and functional impairment. Typically, AF progresses from paroxysmal to more permanent forms, irrespective of management practices and intervention, leading to a significant and independent risk of thromboembolism, cardiac failure and mortality., ${ }^{1,2}$ AF also adversely affects patients' quality of life. ${ }^{3}$

AF has substantial economic impact, particularly due to AF-attributable stroke, the incidence of which is increasing in parallel with ageing populations as treatment remains suboptimal.

The evolving burden of AF has been influenced by a combination of population ageing, changing patterns of cardiac risk factors and improved survival rates in other, contributory forms of cardiovascular disease..$^{1-5}$ As such, reports from high-income countries have demonstrated that AF exerts a major and evolving public health, social and economic burden.

Previously, the overall population prevalence of AF (in all age groups) was reported to be $1.0 \%$ to $2.0 \%$. ${ }^{6,7}$ Recently, prevalence has been shown to be $2.5 \%$ to $4.0 \%$ in adult populations $\geqslant 18$ years. ${ }^{8-10}$ Prevalence of $3.8 \%$ in adults $\geqslant 60$ years has been described, with AF not commonly reported in individuals aged $<55$ years (prevalence $0.1 \%$ ).

Much of the current literature describing AF epidemiology reports on statistics calculated from data derived from North American and European populations ,, $71-14$ and, more recently, from Asian populations. ${ }^{15}$ The number of affected individuals is projected to increase exponentially over the next four decades. ${ }^{7}$ Large population-based

\section{Abstract}

Objective: To estimate the current and future prevalence of atrial fibrillation $(\mathrm{AF})$ in the Australian adult population according to age and sex.

Design: Application of international AF prevalence statistics to Australian adult population data (for people $\geqslant 55$ years) to estimate population prevalence; use of population projections to estimate potential future prevalence of AF.

Main outcome measures: Estimated prevalence of AF in 2014 and future prevalence projected to 2034.

Results: We estimated that at 30 June 2014 there would be 328562 cases of AF among people aged $\geqslant 55$ years (a prevalence of $5.35 \%$; 95\% Cl, 3.79\%-7.53\%), comprising 174986 men (prevalence, 5.97\%; $95 \% \mathrm{Cl}, 4.11 \%-8.54 \%$ ) and 153576 women (prevalence, $4.79 \% ; 95 \% \mathrm{Cl}$, $3.50 \%-6.60 \%$ ). Without significant changes to the natural history of $\mathrm{AF}$, by 2034 this figure is projected to rise to over 600000 (prevalence, 6.39\%; $95 \% \mathrm{Cl}, 4.56 \%-8.90 \%$ ), with a prevalence of $7.22 \%$ among men (95\% $\mathrm{Cl}, 4.99 \%-10.28 \%)$ and $5.64 \%(95 \% \mathrm{Cl}, 4.18 \%-7.64 \%)$ among women. The greatest projected regional increase in prevalence between 2014 and 2034 is expected in Queensland, with a likely twofold increase (from 61 613 cases to 123142 cases), although New South Wales cases will remain predominant, with a 1.7-fold increase (from 110892 to 191 578). We also predicted that between 2014 and 2034 the number of AF cases would double among older age groups (from 200638 to 414377 individuals aged $\geqslant 75$ years) and would increase 2.5 -fold among men aged $\geqslant 85$ years (from 29370 to 71582 ).

Conclusions: These data are indicative of a largely underappreciated AF prevalence in Australia. They mandate a more systematic effort to both understand and respond to an evolving AF burden.

epidemiological studies assessing the burden of AF in Australia are yet to be undertaken. Of significance, a recent analysis of national data in Australia confirmed a 7.9\% annual increase in hospitalisations due to AF (as a principal diagnosis), with around 45000 hospitalisations attributable to AF per annum. ${ }^{16}$ These data provide further impetus to understand the underlying caseload of AF in Australia.

The primary objective of our study was to estimate the current prevalence of AF in Australian adults most commonly affected by AF (those $\geqslant 55$ years) using robust and reliable population data and international prevalence statistics. A secondary objective was to further estimate the likely prevalence of AF in Australia over the next two decades to 2034 as the population continues to age and the natural history of AF, and therefore its prevalence, remains unchanged.

\section{Methods}

\section{Applying international AF prevalence statistics}

We have previously undertaken a comprehensive review of the epidemiology of AF in high-income countries. ${ }^{8}$ For our current analysis, we assessed seven international epidemiological studies identified in the review and collated statistics to obtain estimates of AF prevalence that would be most applicable to the

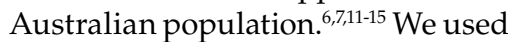
data from studies that provided the most comprehensive age- and sexspecific prevalence estimates (including 95\% confidence intervals) for individuals aged $\geqslant 55$ years. We included studies with a prospective study design that presented more recent data for relatively large samples of relative similarity to the Australian population and with a rigorous method for definitive diagnosis of AF (ie, 
1 Australian adult population (aged $\geqslant 55$ years) and estimated prevalence of atrial fibrillation (AF) at 30 June 2014

\begin{tabular}{|c|c|c|c|c|c|c|c|c|c|}
\hline \multirow[b]{2}{*}{ Age (years) } & \multicolumn{3}{|c|}{$\begin{array}{c}\text { Australian population, } \\
30 \text { Jun 2014* }\end{array}$} & \multicolumn{3}{|c|}{ Assumed prevalence, ${ }^{\dagger} \%(95 \% \mathrm{Cl})$} & \multicolumn{3}{|c|}{ Population with AF at 30 Jun 2014, No. $(95 \% \mathrm{Cl})$} \\
\hline & (a) Men & (b) Women & (c) Total & (d) Men & (e) Women & (f) Total $(\mathrm{i} \div \mathrm{c})$ & (g) Men $(\mathrm{a} \times \mathrm{d})$ & (h) Women $(b \times e)$ & (i) Total $(g+h)$ \\
\hline $55-59$ & 704608 & 722388 & 1426996 & $\begin{array}{c}0.80 \% \\
(0.30 \%-2.10 \%)\end{array}$ & $\begin{array}{c}0.60 \% \\
(0.20 \%-1.50 \%)\end{array}$ & $\begin{array}{c}0.70 \% \\
(0.25 \%-1.80 \%)\end{array}$ & $\begin{array}{c}5637 \\
(2114-14797)\end{array}$ & $\begin{array}{c}4334 \\
(1445-10836)\end{array}$ & $\begin{array}{c}9971 \\
(3559-25633)\end{array}$ \\
\hline $60-64$ & 623635 & 639713 & 1263348 & $\begin{array}{c}2.60 \% \\
(1.60 \%-3.40 \%)\end{array}$ & $\begin{array}{c}1.00 \% \\
(0.50 \%-2.00 \%)\end{array}$ & $\begin{array}{c}1.79 \% \\
(1.04 \%-2.69 \%)\end{array}$ & $\begin{array}{c}16215 \\
(9978-21204)\end{array}$ & $\begin{array}{c}6397 \\
(3199-12794)\end{array}$ & $\begin{array}{c}22612 \\
(13177-33998)\end{array}$ \\
\hline $65-69$ & 554463 & 563844 & 1118307 & $\begin{array}{c}5.20 \% \\
(3.70 \%-7.30 \%)\end{array}$ & $\begin{array}{c}2.90 \%( \\
1.90 \%-4.40 \%)\end{array}$ & $\begin{array}{c}4.04 \% \\
(2.79 \%-5.84 \%)\end{array}$ & $\begin{array}{c}28832 \\
(20515-40476)\end{array}$ & $\begin{array}{c}16351 \\
(10713-24809)\end{array}$ & $\begin{array}{c}45183 \\
(31228-65285)\end{array}$ \\
\hline $70-74$ & 400375 & 417265 & 817640 & $\begin{array}{c}6.90 \% \\
(5.00 \%-9.60 \%)\end{array}$ & $\begin{array}{c}5.40 \% \\
(4.10 \%-7.00 \%)\end{array}$ & $\begin{array}{c}6.13 \% \\
(4.54 \%-8.27 \%)\end{array}$ & $\begin{array}{c}27626 \\
(20019-38436)\end{array}$ & $\begin{array}{c}22532 \\
(17108-29209)\end{array}$ & $\begin{array}{c}50158 \\
(37127-67645)\end{array}$ \\
\hline 75-79 & 288732 & 321994 & 610726 & $\begin{array}{c}13.00 \% \\
(9.80 \%-17.10 \%)\end{array}$ & $\begin{array}{c}6.50 \% \\
(4.70 \%-8.90 \%)\end{array}$ & $\begin{array}{c}9.57 \% \\
(7.11 \%-12.78 \%)\end{array}$ & $\begin{array}{c}37535 \\
(28296-49373)\end{array}$ & $\begin{array}{c}20930 \\
(15134-28657)\end{array}$ & $\begin{array}{c}58465 \\
(43430-78030)\end{array}$ \\
\hline $80-84$ & 195863 & 252391 & 448254 & $\begin{array}{c}15.20 \% \\
(10.50 \%-21.50 \%)\end{array}$ & $\begin{array}{c}12.70 \% \\
(9.70 \%-16.50 \%)\end{array}$ & $\begin{array}{c}13.79 \% \\
(10.05 \%-18.68 \%)\end{array}$ & $\begin{array}{c}29771 \\
(20566-42111)\end{array}$ & $\begin{array}{c}32054 \\
(24482-41645)\end{array}$ & $\begin{array}{c}61825 \\
(45048-83756)\end{array}$ \\
\hline$\geqslant 85$ & 164078 & 291302 & 455380 & $\begin{array}{c}17.90 \% \\
(11.50 \%-26.80 \%)\end{array}$ & $\begin{array}{c}17.50 \% \\
(13.80 \%-21.90 \%)\end{array}$ & $\begin{array}{c}17.64 \% \\
(12.97 \%-23.67 \%)\end{array}$ & $\begin{array}{c}29370 \\
(18869-43973)\end{array}$ & $\begin{array}{c}50978 \\
(40200-63795)\end{array}$ & $\begin{array}{c}80348 \\
(59069-107768)\end{array}$ \\
\hline Total & 2931754 & 3208897 & 6140651 & $\begin{array}{c}5.97 \% \\
(4.11 \%-8.54 \%)\end{array}$ & $\begin{array}{c}4.79 \% \\
(3.50 \%-6.60 \%)\end{array}$ & $\begin{array}{c}5.35 \% \\
(3.79 \%-7.53 \%)\end{array}$ & $\begin{array}{c}174986 \\
(120357-250370)\end{array}$ & $\begin{array}{c}153576 \\
(112281-211745)\end{array}$ & $\begin{array}{c}328562 \\
(232638-462115)\end{array}$ \\
\hline
\end{tabular}

confirmed by electrocardiography). The Rotterdam Study ${ }^{11}$ most explicitly fitted these inclusion criteria.

\section{Estimating current prevalence of AF in Australia}

We obtained data representing the Australian population by single year of age as calculated on 30 June 2014 from the Australian Bureau of Statistics (ABS). ${ }^{17}$ Data for all individuals aged $\geqslant 55$ years were combined into 5-year age brackets (except those aged $\geqslant 85$ years, who were treated as one group). This was undertaken for the overall population and for each state and territory separately. We applied international AF prevalence statistics to each age group and to men and women separately. Ethics approval was not required for this research, as it involved the use of publicly available anonymised data and did not directly involve human participants.

\section{Projecting future prevalence of AF in Australia}

We obtained population projections for 2014 to 2034 from the ABS based on the last census (2011) and representing annual data as at 30 June. These projection data represent the growth and change in the Australian population that would occur if certain assumptions about future fertility, mortality and migration were to prevail over the projection period..$^{18}$ Projections for the total population and by sex were condensed into 5 -year age groups (for people $\geqslant 55$ years). Conservatively, we assumed that AF prevalence would remain stable from 2014 to 2034 and, therefore, the same prevalence statistics were applied. Three main series of projection data were available for use. We chose the series that largely reflects current trends in fertility, life expectancy at birth and net overseas migration. ${ }^{18}$ We also undertook a sensitivity analysis in which the upper and lower limits of prevalence CIs were applied to all data (Appendix 1).

\section{Results}

\section{Estimated prevalence of $\mathrm{AF}$ in 2014}

The estimated prevalence of AF in Australian adults aged $\geqslant 55$ years at 30 June 2014 was 5.35\% (95\% CI, $3.79 \%-7.53 \%$; Box 1) and was greater in men than in women $(5.97 \%$ [95\% CI, $4.11 \%-8.54 \%$ ] v $4.79 \%$ [ $95 \%$ CI, 3.50\%$6.60 \%]$, respectively). However, reflective of global patterns, the number of prevalent cases of AF among women aged $>80$ years is likely to be greater than that among age-matched men. With the exception of men aged 70-74 years and women aged 75-79 years, there was a consistent trend towards more AF cases in successively older age cohorts. Of note, our estimates suggest that among 60-64-year-olds there are currently 2.5 times as many men as women with AF, and among those aged 65-69 or 75-79 years, there are almost twice as many men as women with AF.

Appendix 2 shows the estimated prevalence of AF and case distribution within each Australian state and territory at 30 June 2014. New South Wales was expected to have the highest number of individuals affected by AF overall (110892), and the Northern Territory was expected to have the lowest (1413).

\section{Projected prevalence of $\mathrm{AF}$ in 2034}

We estimated that by 2034 AF prevalence will have increased by $1.04 \%$ in the overall adult population aged $\geqslant 55$ years (to $6.39 \%$; $95 \%$ CI, $4.56 \%-$ $8.90 \%$ ). This comprises an increase of $1.25 \%$ in men and $0.85 \%$ in women, to $7.22 \%(95 \%$ CI, $4.99 \%-10.28 \%)$ and $5.64 \%$ (95\% CI, 4.18\%-7.64\%), respectively (Box 1 and Appendix 3). Thus, owing to population dynamics alone (ie, without any changes in incidence and survival rates), the number of individuals affected by AF in Australia will have almost doubled compared with 2014 - overall, from over 300000 to over 600000 , and for men and women, respectively, from about 
2 Projected number of adults ( 55 years and older) with atrial fibrillation in Australia between 2014 and 2034

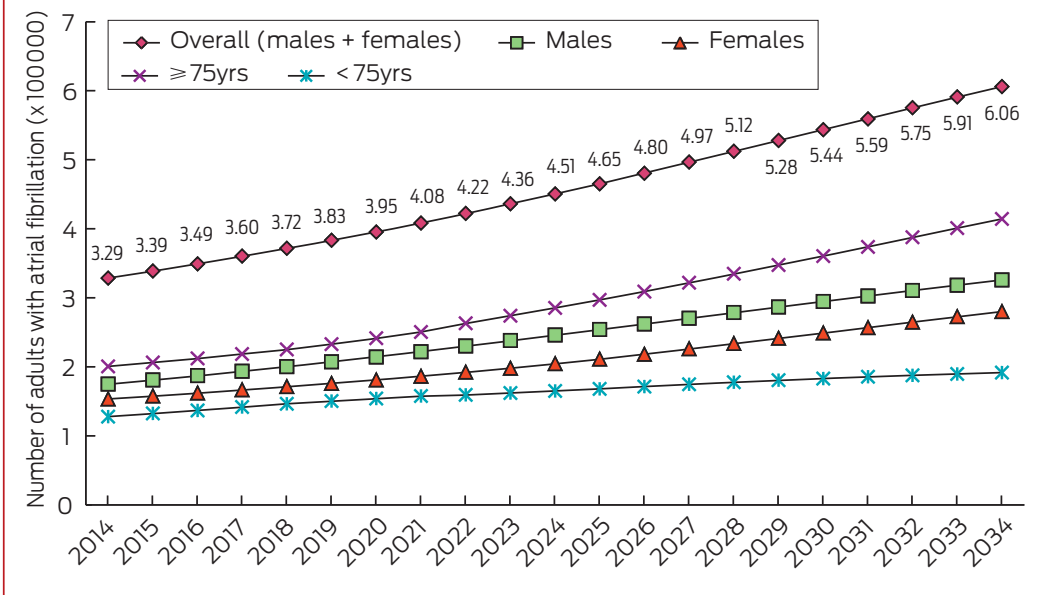

175000 and 150000 in 2014 to about 325000 and 280000 in 2034 (Box 1 and Appendix 3).

About double the number of individuals aged $\geqslant 75$ years will be affected by AF by 2034 (414377 compared with 200638). Similarly, the number of affected men aged $\geqslant 85$ years is predicted to increase by 2.5 -fold (from 29370 to 71582 ).

Appendix 2 also shows the projected number of affected individuals and prevalence of AF within each Australian state and territory in 2034. It is estimated that NSW will still have the highest number of individuals with AF (191578), a 1.7fold increase, but Queensland will have the greatest increase (from 61613 to 123142; twofold). All Australian states and territories are projected to have between 1.7-2.3 times the number of individuals with AF.

\section{A steady increase in AF prevalence predicted between 2014 and 2034}

As shown in Box 2, the number of adults aged $\geqslant 55$ years with AF is predicted to increase steadily in Australia over the next two decades. The number of individuals aged 5574 years with AF is projected to rise at a slower rate than the number of affected individuals aged $\geqslant 75$ years. The difference between the estimated numbers of men and women with AF in 2014 is expected to continue and perhaps widen over time.

\section{Discussion}

Despite global recognition of an increasing burden of AF within the ageing populations of high-income countries, ${ }^{8,19}$ there is a paucity of data to quantify the number of Australians affected by this potentially deadly condition. Using contemporary population data and conservative estimates derived from robust international studies, we estimated that $5.35 \%$ of the adult population aged $\geqslant 55$ years $(5.97 \%$ of men and $4.79 \%$ of women) are currently affected by AF.

\section{Projected rise in Australia}

This proportion is projected to rise to about 1.2 times this value by 2034 , to $6.39 \%$. We predict that between 2014 and 2034 AF will continue to be more prevalent in older age groups and in men compared with women. Of all states and territories, NSW (being the most populous state) will experience the greatest increase in the number of cases (almost doubling, to just under 200000), although the greatest increase in prevalence is expected in Queensland, most likely due to the ageing of an older resident population.

Overall prevalence of AF has risen substantially over recent decades, as shown by European, North American and Asian studies;, 6,711-15 however, there have been no contemporary large-scale, population-based studies conducted to determine AF prevalence in Australia. The last prospective Australian study collecting data specifically on the burden of AF was conducted in Western Australia between 1966 and $1981 .{ }^{20}$ Therefore, the contemporary epidemiological profile and cost burden of AF in Australia cannot be specifically described.

\section{Global observations}

Data from the our report contribute to exploring the size of the AF burden, reflecting global observations of prevalence, including sex and projection patterns. Reported AF prevalence is higher in older individuals, illustrating the influence of ageing; and prevalence in men remains consistently higher than in women, although absolute numbers of affected women are greater.

Our recent pooled analysis of international population data suggests that the prevalence figure (in the adult population $\geqslant 20$ years) is likely to be between $2.5 \%$ and $3.5 \%,{ }^{8}$ supporting the prevalence estimates presented here. Studies have confirmed that the prevalence of AF in communitybased studies ranges between $0.1 \%$ and $4.0 \%$ in individuals aged $\geqslant 15$ years and that overall prevalence of AF in Sweden was 3.0\% (3.4\% in men and $2.6 \%$ in women) in $2010 .{ }^{10}$ The two previous studies assessing AF prevalence in Australia demonstrate consistency with the conservative international estimates applied within our study, providing support for their use within the Australian context. Prevalence was reported to be $4.9 \%$ in WA adults $\geqslant 60$ years $(5.6 \%$ in men, 4.2\% in women) between 1966 and $1981^{20}$ and $4.0 \%$ in adults $\geqslant 30$ years overall $(6.0 \%$ in men, $4.0 \%$ in women) attending general practice in $2000 .{ }^{21}$ Our projections suggesting a pronounced escalation in AF cases in the coming decades match similar projections for European and North American populations. ${ }^{7,19}$

Perhaps the greatest impact of escalating AF prevalence will be economic. AF is associated with a five- to sevenfold increased risk of stroke and a threefold increased risk of heart failure. ${ }^{22}$ Within an ageing population, most costs will be driven by the need to manage stroke risk (via thromboprophylaxis), prevent cardiac dysfunction and manage patients after 
events secondary to AF (via hospitalisation, provision of therapy and increased surveillance). Although current Australian projections predict that prevalent AF cases will almost double in 20 years, others have predicted doubling over 25-35 years in North America. ${ }^{7,23}$ This differential is likely reflective of Australian population growth over the next two decades that will be shaped by increased international migration, urbanisation and population mobility.

\section{Limitations}

Some specific limitations of our work require comment. In order of importance: first, it is unknown whether the international prevalence statistics obtained from the Rotterdam Study are applicable to the Australian population and what the implications are of applying them. AF is known to be more prevalent in individuals of European ancestry, ${ }^{8}$ so the applied statistics may not translate to the increasingly multicultural Australian population. The prevalence of AF in Australian Aboriginal and Torres Strait Islanders remains unknown, but is potentially higher than in white Australians due to the increased cardiovascular disease burden within this population. ${ }^{24}$ Consequently, the selection of these international prevalence statistics may result in the over- or underestimation of prevalence within this population.

Second, increasing disease awareness, potential introduction of broad screening programs, and the ageing population will influence the incidence of AF. For example, single time-point AF screening identified an overall incidence of previously unknown AF of $1.0 \%$ (1.4\% in those $\geqslant 65$ years), of whom $67 \%$ were at high risk of stroke. ${ }^{25}$

Next, projections must be interpreted with some caution, given that certain factors may negatively or positively affect AF incidence and survival rates (fundamental drivers of prevalence). The current impact of antecedents and comorbidities of AF (eg, hypertension, obesity, obstructive sleep apnoea, diabetes, acute coronary syndrome) may change over time owing to increasing prevalence or improved therapies and management, suggesting that projections may potentially under- or overestimate prevalence, depending on the factors considered. The true prevalence of asymptomatic and paroxysmal forms of AF also remains unknown, potentially resulting in prevalence underestimation.

Finally, research will lead to acquisition of new knowledge on the natural history, treatment and progression of AF; for example, the development and introduction of novel therapeutics for management, which will have positive influences on survival. Assumptions were made when population projections were calculated; most critically, we assumed that AF prevalence remained static over time. Next, we chose population projections that largely reflect current trends in fertility, life expectancy and migration. We did not determine low and high estimates founded on alternative assumptions.

\section{Conclusion}

Our data provide a snapshot of the potential current and future impact of AF in Australia. They support the expectation that AF will reach epidemic proportions worldwide in the coming decades. Large-scale, population-based studies are required to ascertain the true burden of AF, including social, health and economic (direct and indirect) costs. Understanding this burden is premised on the availability of highquality epidemiological studies. The increasing prevalence of AF will greatly influence health care systems and communities. Therefore, substantial integrated efforts to understand the complex causes and clinical presentation of AF in Australia are required to attenuate the large economic, social and individual costs associated with this potentially fatal cardiac condition. ${ }^{26}$

Acknowledgements: All authors are supported by the National Health and Medical Research Council (NHMRC) of Australia. This research was supported in part by the Victorian Government's Operational Infrastructure Support program. The NHMRC and Victorian Government had no involvement in the writing or preparation of this manuscript.

Competing interests: No relevant disclosures.

Received 21 Feb 2014, accepted 03 Sep 2014. 
1 Kannel WB, Wolf PA, Benjamin EJ, Levy D. Prevalence, incidence, prognosis, and predisposing conditions for atrial fibrillation: population-based estimates. Am J Cardiol 1998; 82: 2N-9N.

2 Benjamin EJ, Wolf PA, D’Agostino RB, et al. Impact of atrial fibrillation on the risk of death: the Framingham Heart Study. Circulation 1998; 98: 946-952.

3 Thrall G, Lane D, Carroll D, Lip GY. Quality of life in patients with atrial fibrillation: a systematic review. Am J Med 2006; 119: 448. el-448.el9.

4 Stewart S, Murphy NF, Walker A, et al. Cost of an emerging epidemic: an economic analysis of atrial fibrillation in the UK. Heart 2004; 90 : 286-292.

5 Ringborg A, Nieuwlaat R, Lindgren P, et al Costs of atrial fibrillation in five European countries: results from the Euro Heart Survey on atrial fibrillation. Europace 2008; 10 : 403-411.

6 Stewart S, Hart CL, Hole DJ, McMurray JJ. Population prevalence, incidence, and predictors of atrial fibrillation in the Renfrew/ Paisley study. Heart 2001; 86: 516-521.

7 Go AS, Hylek EM, Phillips KA, et al. Prevalence of diagnosed atrial fibrillation in adults: national implications for rhythm management and stroke prevention: the AnTicoagulation and Risk Factors in Atrial Fibrillation (ATRIA) Study. JAMA 2001; 285: 2370-2375.

8 Ball J, Carrington MJ, McMurray JJ, Stewart S. Atrial fibrillation: profile and burden of an evolving epidemic in the 21st century. Int $J$ Cardiol 2013; 167: 1807-1824.

9 Lip GY, Brechin CM, Lane DA. The global burden of atrial fibrillation and stroke: a systematic review of the epidemiology of atrial fibrillation in regions outside North
America and Europe. Chest 2012; 142: 1489-1498.

10 Norberg J, Bäckström S, Jansson JH, Johansson L. Estimating the prevalence of atrial fibrillation in a general population using validated electronic health data. Clin Epidemiol 2013; 5: 475-481.

11 Heeringa J, van der Kuip DA, Hofman A, et al. Prevalence, incidence and lifetime risk of atrial fibrillation: the Rotterdam study. Eur Heart J 2006; 27: 949-953.

12 Wolf PA, Benjamin EJ, Belanger AJ, et al. Secular trends in the prevalence of atrial fibrillation: the Framingham Study. Am Heart J 1996; 131: 790-795.

13 Furberg CD, Psaty BM, Manolio TA, et al. Prevalence of atrial fibrillation in elderly subjects (the Cardiovascular Health Study). Am J Cardiol 1994; 74: 236-241.

14 Smith JG, Platonov PG, Hedblad B, et al. Atrial fibrillation in the Malmö Diet and Cancer study: a study of occurrence, risk factors and diagnostic validity. Eur J Epidemiol 2010; 25 . 95-102

15 Chien KL, Su TC, Hsu HC, et al. Atrial fibrillation prevalence, incidence and risk of stroke and all-cause death among Chinese. Int J Cardiol 2010; 139: 173-180.

16 Wong CX, Brooks AG, Leong DP, et al. The increasing burden of atrial fibrillation compared with heart failure and myocardial infarction: a 15-year study of all hospitalizations in Australia. Arch Intern Med 2012; 172: 739-741.

17 Australian Bureau of Statistics. Australian demographic statistics, Dec 2013. Canberra: ABS, 2013. (ABS Cat. No. 3101.0.) http://www. abs.gov.au/ausstats/abs@.nsf/mf/3101.0 (accessed Jan 2013).

18 Australian Bureau of Statistics. Population projections, Australia, 2012 (base) to 2101.
Canberra: ABS, 2013. (ABS Cat. No. 3222.0.) http://www.abs.gov.au/Ausstats/abs@.nsf/ mf/3222.0 (accessed Jan 2013).

19 Naccarelli GV, Varker H, Lin J, Schulman KL. Increasing prevalence of atrial fibrillation and flutter in the United States. Am J Cardiol 2009; 104: 1534-1539.

20 Lake FR, Cullen KJ, de Klerk NH, et al. Atrial fibrillation and mortality in an elderly population. Aust N Z J Med 1989; 19: 321-326.

21 Sturm JW, Davis SM, O'Sullivan JG, et al. The Avoid Stroke as Soon as Possible (ASAP) general practice stroke audit. Med J Aust 2002; 176: 312-316.

22 Chugh SS, Blackshear JL, Shen WK, et al. Epidemiology and natural history of atrial fibrillation: clinical implications. J Am Coll Cardiol 2001; 37: 371-378.

23 Miyasaka Y, Barnes ME, Gersh BJ, et al. Secula trends in incidence of atrial fibrillation in Olmsted County, Minnesota, 1980 to 2000 , and implications on the projections for future prevalence. Circulation 2006; 114: 119-125.

24 Australian Institute of Health and Welfare. Cardiovascular disease: Australian facts 2011. Canberra: AlHW, 2011. (AlHW Cat. No. CVD 53; Cardiovascular Disease Series No. 35.) http://www.aihw.gov.au/publicationdetail/?id=10737418510 (accessed Sep 2014)

25 Lowres N, Neubeck L, Redfern J, Freedman SB. Screening to identify unknown atrial fibrillation. A systematic review. Thromb Haemost 2013; 110: 213-222.

26 Stewart S, Ball J, Horowitz JD, et al. Standard versus atrial fibrillation-specific management strategy (SAFETY) to reduce recurrent admission and prolong survival: pragmatic, multicentre, randomised controlled trial. Lancet 2014; Nov 17 [Epub ahead of print]. doi:10.1016/S0140-6736(14)61992-9. 